\title{
Q: Where is the Wealth of Nations? A: In Communities.
}

\author{
Michael Gurstein, Ph.D. \\ Editor-in-chief < editori@ci-journal.net >
}

\begin{abstract}
This issue of JoCI has as its lead an important article by Michael Arnold making the case for the conceptual (and thus theoretical) autonomy of a specifically "community" informatics. This elegantly and forcefully argued paper draws upon a range of sources and analytical insights from theorists not often cited in social science or information systems research all to make the case that communities have to be understood as being more than the sum of their parts and that the systems that support these must integrate these insights into their design and formulation.
\end{abstract}

In this way the paper is linking back into several of the papers from the previous issue on CI and Systems Design and linking forward into the potential for a rich vein of theoretical analysis and discussion. Perhaps of most significance for Community Informatics is the strength and clarity of the argument indicating the necessity for a "Community Informatics" rather than for ICTs as simple supports for communities or of communities simply going out into the marketplace to find the tools to support them..

Garth Graham in his "Point of View" makes a quite parallel argument concerning the independent status of life lived online (within the network) as compared to life outside of the network and of the degree of overall transformation (including in the nature of the policy environment) which such a development implies. Adomi, Furuholt and Kristiansen, Kwapong,. Eubanks, Denison and Johanson -- drawing on experience from multiple contexts in multiple countries give case study evidence of the way in which an appropriation of the use of ICTs is transforming personal, family, community and organizational behaviours, activities, expectations and outcomes. In most cases these have not as yet led directly to the kind of collective enablement or empowerment that Arnold is suggesting as being the ultimate outcome of a Community Informatics but each in their own way documenting way stations along that path.

Acevedo's piece quite nicely bookends Arnold's paper by looking at community networking not as product but rather as process and specifically as a process which has measurable and desirable outcomes in the form of "network capital". Coincidentally, a report recently released by the World Bank discusses in some detail and goes forward to directly quantify the value of the social, cultural, legal and political context within which economic activity takes place as a contributor to "development". Not surprisingly the World Bank's study finds that the value of the contribution of a stable, orderly, rule governed context for production adds enormously to the possibility and thus the value of productive labour. ${ }^{\mathrm{i}}$

So it is possible to look on this and other issues of JoCI and of Community Informatics overall as at least a partial answer to the World Bank's rhetorical question - Where is the Wealth of Nations? In fact, the Wealth of Nations is found in a nation's communities which are the anchor and the context of for the life of its citizens. The conclusion to draw is that the value of ICT can be found in its being one means, and a particularly useful, dynamic and potentially widely inclusive one, for unlocking and realizing that potential.

It is the contention of CI and the argument implicit in the various papers in this and other issues, that ICT working in and through communities has the potential to ensure that the opportunity for a contribution to productive value as identified by the Bank is realized both in Less Developed as well as Developed countries and among marginalized populations everywhere. 
i Where is the Wealth of Nations? Measuring Capital for the 21st Century The World Bank, Washington, D.C., 2006 